\title{
LETTER
}

\section{Persistent left vena cava incidentally recognized during subclavian vein catheterization}

\author{
Julien Bordes*, Yves Asencio, Erwan d'Arranda and Philippe Goutorbe
}

Central venous line insertion is a routine procedure in the intensive care unit. But intensivists should be aware of the possibility of rare anatomic variants. We report an 84-year-old patient who was admitted to the intensive care unit for respiratory distress due to Guillain-Barré syndrome. After intubation of the trachea, a central venous catheter was inserted via the left subclavian vein. This was accomplished uneventfully with only one puncture. However, the post-procedural chest $\mathrm{x}$-ray showed an unusual left-sided paramediastinal course of the catheter (Figure 1). We evocated an arterial placement first, but the transduced waveform and the blood gas samples were compatible with an intrathoracic vein placement. So we hypothesized that the patient could present with a persistent left superior vena cava (LSVC). This diagnosis was confirmed by transoesophageal echography: the injection of agitated saline via the right cubital vein resulted in opacification of the dilated coronary sinus prior to reaching the right atrium and right ventricle, and this confirmed the anatomic variant of LSVC associated with the absence of a right superior vena cava. There were no other abnormalities concerning heart or great vessels.

Persistent LSVC occurs in $0.5 \%$ of the population and $5 \%$ to $10 \%$ of patients with congenital heart diseases. It usually drains into the right atrium through the coronary sinus, and it is associated with an absent right superior vena cava in $20 \%$ of cases [1]. The diagnosis can be made by bedside transthoracic or transesophageal echocardiography $[2,3]$. Computed tomography can also be useful [4]. Persistent LSVC is not a contraindication to subclavian vein catheterization but can make difficult the attempt to place a central venous line, pulmonary artery catheter, or pacemaker. Some authors described the uneventful use of a catheter placed in the LSVC for several days, after checking that the catheter tip was not in the coronary sinus [3]. The use of a pulmonary artery catheter has also been reported [1]. But manipulation of a

*Correspondence: bordes.julien@neuf.fr

Department of Intensive Care, Sainte Anne Hospital, Boulevard Sainte Anne, 83800 Toulon, France

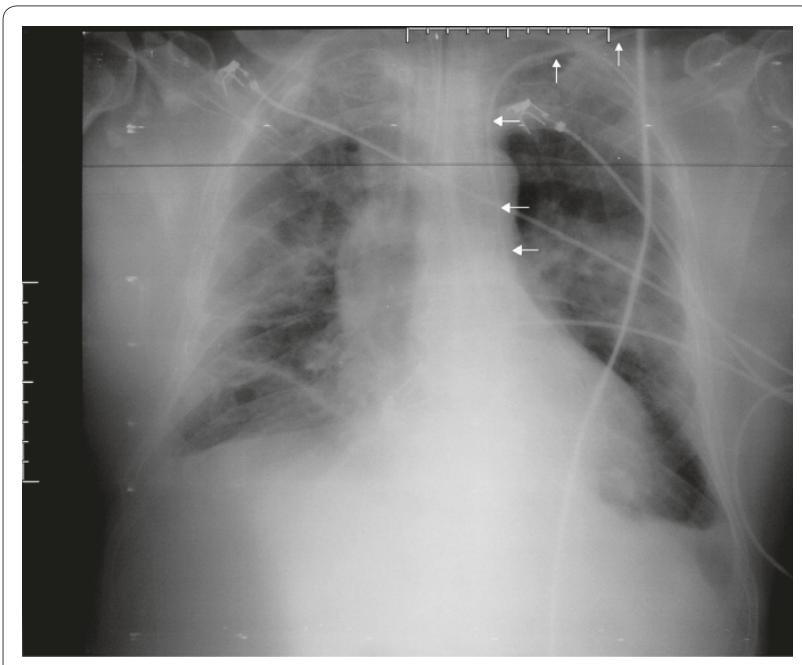

Figure 1. Post-procedural chest x-ray showing a central venous catheter taking a left paramediastinal course (arrows).

catheter through the coronary sinus may result in hypotension, angina, or cardiac rhythm trouble.

\section{Abbreviation}

LSVC = left superior vena cava.

\section{Acknowledgments}

Written consent for publication was obtained from the patient's relative.

Competing interests

The authors declare that they have no competing interests.

Published: 15 February 2010

\section{References}

1. Ould-Ahmed M, Mas B, Hautbois E, Garcia JF, Caroff P, Guiavarch M: [Unusual course of a pulmonary artery catheter through a persistent superior vena cava]. Ann Fr Anesth Reanim 2000, 19:745-748.

2. Voci P, Luzi G, Agati L: Diagnosis of persistent left superior vena cava by multiplane transesophageal echocardiography. Cardiologia 1995, 40:273-275.

3. Higgs AG, Paris S, Potter F: Discovery of left-sided superior vena cava during central venous catheterization. Br J Anaesth 1998, 81:260-261.

4. Heye T, Wengenroth M, Schipp A, Johannes Dengler T, Grenacher L, Werner Kauffmann G: Persistent left superior vena cava with absent right superior vena cava: morphological CT features and clinical implications. Int J Cardiol 2007, 116:e103-105.

doi:10.1186/cc8840

Cite this article as: Bordes J, et al:: Persistent left vena cava incidentally recognized during subclavian vein catheterization. Critical Care 2010, 14:405. 